doi:10.17659/01.2021.0008

Journal of Case Reports 2021;11(1):28-31

\title{
Simple Bone Cyst Treated with Decompression and Percutaneous Steroid Injection: A Case Series
}

\author{
Achmad Fauzi Kamal, Felais Hediyanto Pradana \\ Department of Orthopaedic and Traumatology, Cipto Mangunkusumo General Hospital/ Faculty of Medicine Universitas \\ Indonesia.
}

\section{Corresponding Author:}

Dr Felais Hediyanto Pradana

Email: deazfelais@gmail.com

This is an Open Access article distributed under the terms of the Creative Commons Attribution License (creativecommons.org/ licenses/by/3.0).

Received Accepted

Published

August 22, 2020

November 6, 2020

February 10, 2021

\begin{abstract}
Background: Simple bone cyst (SBC) is a rare benign tumor-like lesion and most frequently occurs in children and adolescents. There is still no official consensus to treat them. A report stated that decompression and percutaneous steroid injections (PSI) into the cyst yielded $96 \%$ positive results. Case Series: We identified all patients who were treated by decompression and PSI during 2013 and 2020. Sixteen cases reported in this serial case consists of 13 males and 3 females. The average age of these subjects is 8.5 years. Musculoskeletal Tumor Society (MSTS) functional score in 15 cases (94\%) showed very good results, while $1(6 \%)$ case showed fair result after $3^{\text {rd }}$ injection of steroid. Decompression and percutaneous steroid injection therapy for SBC yielded good outcome. Conclusion: Follow-up after procedure of our patients shows very good functional outcome. Therefore, we recommend this procedure as treatment for SBC cases.
\end{abstract}

Keywords: Bone Cysts, Decompression, Injections, Steroids.

\section{Introduction}

Simple bone cysts (SBC) also known as unicameral bone cysts (UBC) are benign, fluid-filled, single chambered tumor-like lesions. SBC is rare and mostly occurs in the children and adolescents. Males are more frequent involved than females with comparison of $3: 1$. The most common site is on the metaphyseal region of proximal humerus and femur. Approximately, 3\% of all skeletal tumors are SBC. Sixty-six percent of SBC patients had pathological fracture complication. It may produce pain, swelling, or stiffness at the joint. SBCs often are diagnosed as an incidental finding on a radiograph [1].

The diagnosis of SBC is established by conventional radiographs and Magnetic Resonance Imaging (MRI). It is well-circumscribed, radiolucent lesion located centrally in diaphysis or metaphysis of long bone with sclerotic margins in conventional x-ray. Rarely, simple bone cysts may be found on the diaphysis and appear as a large, multicameral with slight expansion. In the presence of fracture, the "fallen fragment "sign is noted. A gas bubble that has migrated upward ("rising bubble sign") is also described for SBC. MRI demonstrates presence of fluid and confirms its cystic nature.

The aim of treatment is to promote cyst healing, manage pathological fracture, prevent cyst recurrence and re-fracture [1,2]. However, the treatment remains controversial and treatment modalities have been proposed ranging from curettage and bone grafting, autogenous injection of bone marrow, multiple drilling of cysts wall, flexible intramedullary nail, and decompression with injections of steroids [1-3]. This present studies reports the outcome and follow up of more patients who were treated by decompression and steroid injections in our institution. 


\section{Case Series}

The data was collected from patients with SBC who were treated in our hospital between 2013 until 2020. The SBC was diagnosed by radiographs and MRI. We evaluated functional outcomes in first 10 patients by musculoskeletal tumor society (MSTS) and radiographic pre and post-treatment evaluation while next 6 patients were evaluated using Chang criteria. MSTS scoring system is divided into 4 categories, with the maximum score being 30; score $<25 \%$ of maximal score is categorized as bad, 25 $49 \%$ is categorized as fair, $50-74 \%$ is categorized as good and $>75 \%$ is categorized as very good. As our previous study, the decompression and PSI treatment in our institution was performed under general anesthesia, under $\mathrm{C}$-arm guidance, core bone needles no. 11 are introduced in the proximal and the distal pole of the cystic lesion, fluid from cyst was sent for histopathology, after emptying SBC hemorrhagic fluid is aspirated, cavity flushed with normal saline and with closed distal core bone needle, we perform PSI 80-120 mg [3].

This study included 16 cases, demographic details of which are included in Table 1. We followed-up each patient every month until $3^{\text {rd }}$ decompression and PSI was complete, and every 6 months thereafter [Fig.1,2]. Successful clinical outcomes with very good MSTS score was observed in 14 of $16(87 \%)$ and all cases $100 \%$ in 3 and 6 months after $3^{\text {rd }}$ decompression and PSI, respectively. MSTS scoring evaluation of this study is presented on the Table 2. We noted only one recurrent case in response to treatment in our study during follow-up. Bone healing was assessed using Chang Criteria for radiological examination.

\section{Discussion}

In this study, we found that the prevalence of $\mathrm{SBC}$ is more common in males than in females (13:3) and this is similar to the previous studies. We also found that SBCs occur most frequently in children and adolescents. In our series, 10 of $16(62 \%)$ cases

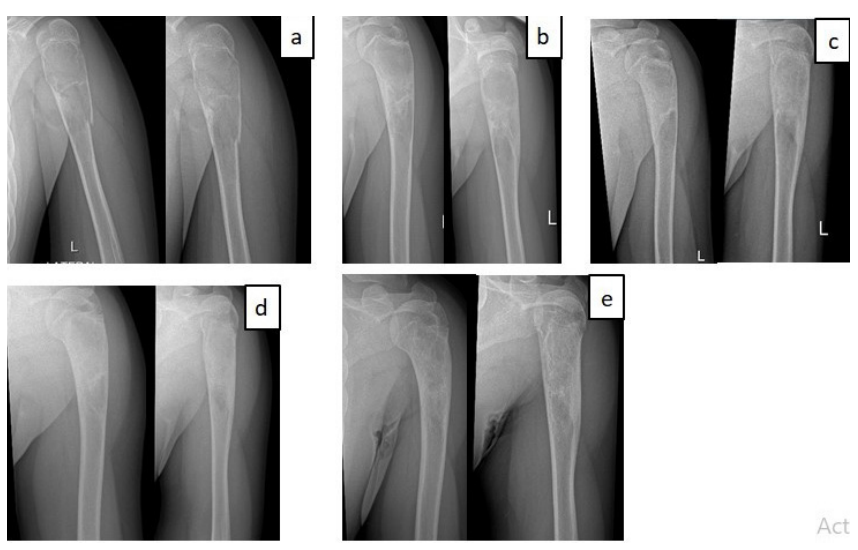

Fig.1: Radiology evaluation in patient with $S B C$ on left humerus; (a) pre injection; (b) 1-month post 1st injection; (c) 1-month post $2^{\text {nd }}$ injection; (d) 1 month post $3^{\text {rd }}$ injection; (e) 6-months follow-up.

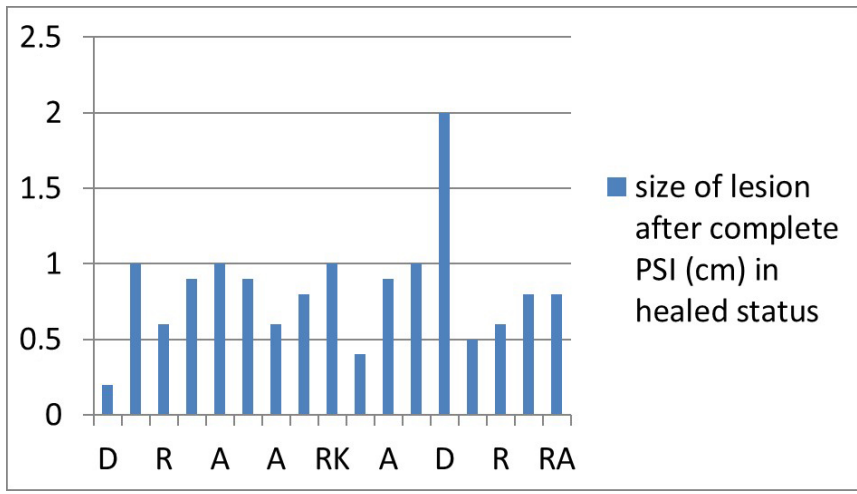

Fig.2: The size of the SBC lesion in radiographic examination after complete PSI in $\mathrm{cm}$.

were located in humerus, followed by $5(31 \%)$ in the femur and $1(6 \%)$ in the calcaneus. This shown similar trend with previous studies.

Pathological fracture was found significantly more common in humerus than femur in this study and previous studies. SBCs located in humerus usually remain undetected, unlike in femur. The absence of weight bearing in humerus and subsequent expansion causes to manifest as pathological fracture due to trivial injury [1]. Steroids act by enhancing bone healing by decompressing the cyst pressure after aspiration of the fluid or by reducing the fluid production with its anti-prostaglandin effect inside the cyst [4]. The 
Table 1: Patient's demographic profile.

\begin{tabular}{|ll|}
\hline Characteristic & $\mathbf{N}=\mathbf{1 6}(\mathbf{\%})$ \\
\hline Age (mean \pm SD) & $8.50 \pm 3.65$ yrs \\
\hline Age Group & \\
$\bullet$ 0-10 yrs & $11(68)$ \\
$\bullet 11-20$ yrs & $5(32)$ \\
\hline Sex & \\
$\bullet$ Male & $13(81)$ \\
$\bullet$ Female & $3(19)$ \\
\hline Location & \\
$\bullet$ Humerus & $10(62)$ \\
$\bullet$ Femur & $5(31)$ \\
$\bullet$ Calcaneus & $1(7)$ \\
\hline Site & \\
$\bullet$ Right & $8(50)$ \\
$\bullet$ Left & $8(50)$ \\
\hline Pathological Fracture & \\
$\bullet$ & $6(38)$ \\
$\bullet$ Yes & $10(62)$ \\
\hline
\end{tabular}

efficacy of decompression and PSI therapy in SBC patients in previous studies is still controversial $[5]$.

We performed the same set of procedures as in our previous study, that all patients were treated with 3 times decompression and PSI with 1-month interval for each injection [3]. The selection of number of injections was based on several previous studies $[5,6]$. In this study, the patient's functional outcomes were evaluated using MSTS scoring system [Fig.1]. The fair result was consistent with the radiographic result which shows that there was recurrent cyst. We measured the radiographic outcomes in this study by using Chang criteria [7]. In this study, radiographic examination was performed before first injection, as well as 1 month after $1^{\text {st }}, 2^{\text {nd }}$ and $3^{\text {rd }}$ decompression and PSI, respectively.

Our results are comparable with several previous studies. A meta-analysis study showed that radiological healing after steroid injection for
Table 2: MSTS scoring evaluation.

\begin{tabular}{|lc|}
\hline \multicolumn{1}{|l|}{ Time of Evaluation } & MSTS score (\%) \\
\hline Pre Procedure & \\
Bad & $(30)$ \\
Fair & $12(70)$ \\
Good & $0(0)$ \\
Very Good & $0(0)$ \\
\hline 1 month after $1^{\text {st }}$ decompression and PSI \\
Bad & $0(0)$ \\
Fair & $5(30)$ \\
Good & $11(70)$ \\
Very Good & $0(0)$ \\
\hline 1 month after $2^{\text {nd }}$ decompression and PSI \\
Bad & $0(0)$ \\
Fair & $0(0)$ \\
Good & $7(50)$ \\
Very Good & $9(50)$ \\
\hline 1 month after $3^{\text {rd }}$ decompression and $P S I$ \\
Bad & $0(0)$ \\
Fair & $0(0)$ \\
Good & $6(30)$ \\
Very Good & $10(70)$ \\
\hline 3 month after $3^{\text {rd }}$ & decompression and PSI \\
Bad & $0(0)$ \\
Fair & $0(0)$ \\
Good & $2(10)$ \\
Very Good & $14(90)$ \\
\hline 6 month after $3^{\text {rd }}$ & decompression and PSI \\
Bad & $0(0)$ \\
Fair & $1(6)$ \\
Good & $0(0)$ \\
Very Good & $15(94)$ \\
\hline
\end{tabular}

simple bone cysts is achieved in $83.6 \%$ cases [8]. In our study, the clinical outcomes were consistent with radiological outcomes. Previous case series also showed a satisfactory radiological and clinical outcomes following steroid injection $[9,10]$.

According to previous research, the relationship between basic characteristics with bone healing and SBC recurrence remains 
controversial. Chang et al. showed that there was significant relationship between the size of the cyst and the patient's age. It was reported to be a reliable predictor, with children $>10$ years of age having a higher rate of cyst healing than those $<10$ years [7]. On the contrary, Hashemi-Nejad and Cole stated that there was no significant relationship between radiology results and cyst size, type or age [10]. Extra care should be taken when administering steroid injection, due to its possible adverse effect.

\section{Conclusion}

Decompression and percutaneus steroid injection therapy for SBC yielded good outcome. The bone healing is relatively fast, has a simple operation procedure, is widely available, has less side effects, very low complication, and recurrence rate. Follow-up after procedure of our patients also shows very good functional outcome. Therefore, we recommend this procedure as treatment for SBC cases.

Contributors: AFK: Patient management and preparation of draft manuscript; FHP: patient management and critical inputs into the manuscript; AFK acted as study guarantor. Both authors approved the final version of the manuscript and are responsible for all aspects of the study.

Funding: None; Competing interests: None stated.

\section{References}

1. Ulici A, Balanescu R, Topor L, Barbu M. The modern treatment of the simple bone cysts. J Med Life. 2012;5(4):469-473.

2. Flont P, Kolacinska-Flont M, Niedzielski K. Factors predictive of positive response to steroid therapy in simple bone cysts: An old trick that still works. Int Orthop. 2013;37(8):1519-1525.

3. Kamal AF, Ajiantoro, Prabowo Y. Simple bone cyst treated with percutaneous steroid injection. Asian J Pharm Clin Res. 2018;11(5):186-190.

4. Kao ST, Scott DD. A review of bone substitutes. Oral Maxillofac Surg Clin North Am. 2007;19(4):513-512.

5. Scaglietti O, Marchetti PG, Bartolozzi P. The effects of methylprednisolone acetate in the treatment of bone cysts. Results of three years follow-up. J Bone Jt Surg Ser B. 1979;61(2):200-204.

6. Campanacci M, Capanna R, Picci P. Unicameral and aneurysmal bone cysts. Clin Orthop Relat Res. 1986;204:26-36.

7. Chang $\mathrm{CH}$, Stanton RP, Glutting J. Unicameral bone cysts treated by injection of bone marrow or methylprednisolone. J Bone Jt Surg - Ser B. 2002;84(3):407-412.

8. Kadhim M, Thacker M, Kadhim A, Holmes L. Treatment of unicameral bone cyst: Systematic review and meta analysis. J Child Orthop. 2014;8(2):171-191.

9. Faisham W, Nawaz A, Ezane A, Zulmi W, Ibrahim S, Abdul Halim A. Non-operative treatment versus steroid injections in the management of unicameral bone cysts. Malaysian Orthop J. 2011;5(2):11-14.

10. Hashemi-Nejad A, Cole WG. Incomplete healing of simple bone cysts after steroid injections. J Bone Jt Surg - Ser B. 1997;79(5):727-730. 